\title{
Effect of implementing infection control guidelines on minimizing surgical wound infection for patients undergoing neurosurgery
}

\author{
Rasha Ali Ahmed Abdelmowla*1, Abdelhakeem A. Essa ${ }^{2}$ \\ ${ }^{1}$ Department of Medical Surgical Nursing, Faculty of Nursing, Assiut University, Assiut, Egypt \\ ${ }^{2}$ Department of Neurosurgery, Faculty of Medicine, Assiut University, Assiut, Egypt
}

Received: August 6, 2018

DOI: $10.5430 /$ jnep.v9n2p98

\author{
Accepted: October 10, 2018 \\ Online Published: October 24, 2018
}

URL: https://doi.org/10.5430/jnep.v9n2p98

\begin{abstract}
Background and objective: Nursing role delivered at all levels of care is critical to eliminate surgical wound infection after neurosurgery. Aim: Evaluate the effect of implementing infection control guidelines on minimizing surgical wound infection for patients undergoing neurosurgery.

Methods: Pretest/posttest was used to assess and evaluate nurses' practices pre and post implementation of infection control guidelines while posttest only was used for patients to evaluate the effect of implementing infection control guidelines on minimizing surgical wound infection. Thirty-six nurses in neurosurgery department at Assiut Neurological, Psychiatric and Neurosurgery University Hospital, also 443 patients undergoing neurosurgery were included. Nurses' practices were assessed pre and post implementation of infection control guidelines. Tools: Nurses' observation checklist, patients' assessment sheet, patients' follow up sheet and neurosurgery infection control guidelines (teaching booklet) for nurses.

Results: Nurses' practices were improved, infection in neurosurgery was eradicated according to results of environmental swabs and surgical wound infection was reduced post implementation of infection control guidelines.

Conclusion and recommendation: Proper implementation of disinfection and sterilization enhance safe and effective care. Infection control policy should be developed in neurosurgery department and all healthcare team should be responsible to adhere and implement it.
\end{abstract}

Key Words: Infection control guidelines, Surgical wound infection, Neurosurgery

\section{INTRODUCTION}

Surgical wound infection is considered one of the most common healthcare associated infections among postoperative patients associated with considerable morbidity and mortality, poor outcome, increase hospital stay, reoperation, readmission, and excessive healthcare costs. It accounts for $20 \%$ to $25 \%$ of all hospital-acquired infections. Yearly incidence in United States ranges from 160,000 to 300,000. ${ }^{[1]}$
United States Center for Disease Control classifies surgical wound infection as superficial, deep or organ space. Superficial infection appears within 30 days after surgery affecting only the skin and subcutaneous tissues and is manifested by pain/tenderness, redness, swelling and/or purulent discharge. Deep infection appears within 30 days or more and is manifested by pain/tenderness, fever, dehiscence, abscess and/or purulent discharge from deep tissues. Organ space infection

*Correspondence: Rasha Ali Ahmed Abdelmowla; Email: rashaali249@yahoo.com; Address: Faculty of Nursing, Assiut University, Assiut, Egypt. 
occurs after 30 days of surgery and may take 1 year to appear. It appears in any part of the anatomy (organs or spaces) other than the incision and is manifested by pain/tenderness, fever, abscess and/or purulent discharge from a drain. ${ }^{[2]}$

All surgical team members must understand risk factors for surgical site infection and implement effective infection control guidelines to overcome its consequences on both patients and hospitals. Causes and risk factors for surgical wound infection in neurosurgery include the following: old age, nicotine use, steroid use, malnutrition, underlying illness, prolonged hospital stay, preoperative shaving of the surgical site the night before surgery, improper skin preparation, infected or colonized surgical personnel, unsafe surgical environment to receive the patients, do not follow principles of aseptic technique during procedures, cerebrospinal fluid leak, use of instrumentations, excessive blood loss, blood transfusion, prolonged operation time and prior surgery. ${ }^{[3,4]}$

Florence Nightingale was considered the first infection control nurse. She established the relation between nursing and infection control in 1854. She provided services to victims of war in a military hospital of Scutari. She claimed that number of deaths will be reduced if hygienic condition of the hospital was improved. ${ }^{[5]}$

World Health Organization and other studies recommended guidelines for prevention of surgical wound infection: healthcare personnel must wear goggles, masks, gowns, and gloves to provide barrier protection. Also, operating rooms environment and patients care areas serve as reservoirs for a variety of microorganisms. So, environmental considerations of operating rooms must be performed to decrease surgical wound infection. Operating theatres should be cleaned routinely. Minimizing airborne contamination by ventilation system of the operating rooms; clean air should be supplied through high-efficiency particulate air filters and a positive pressure maintained. All staff members in the operating rooms have a key role in minimizing contaminated airborne particles by ensuring that all principles of infection control are followed before, during and after surgery. ${ }^{[6-9]}$

Nurses and neurosurgeons should implement interventions that minimize incidence of surgical site infection: counsel patients to completely refrain from smoking for at least 4-6 weeks before neurosurgery. Control of blood sugar level before, during and after neurosurgery is important regardless of diabetic status. Hair in the surgical site should be removed just before surgery and use clippers instead of razors. ${ }^{[10,11]}$ Administer prescribed antibiotic, monitor vital signs, use sterile technique for wound dressing change, monitor for manifestations of wound infection, and teach them how to care for wound at home and to report to neurosurgeons any manifestations of wound infection. ${ }^{[12]}$

Because of major consequences of surgical site infection following neurosurgery, even small percent is very dangerous. According to results of infection control unit and laboratory at Assiut University Hospitals, environmental swabs that were taken from neurosurgery department (in-patients) and neurosurgery operating theatres demonstrated high percent of infection during the last few years. ${ }^{[13,14]}$ Also, large number of patients (32 out of 438) through a period of 6 months (January 2016 to June 2016) before conducting our study were experienced surgical wound infection after various neurosurgical procedures led to increasing length of postoperative hospital stay, excessive healthcare costs, higher rates of hospital readmission, and deteriorating patients' outcomes. ${ }^{[15]}$ So, this study was conducted to implement infection control guidelines to minimize surgical wound infection following neurosurgery.

\subsection{Aim}

Evaluate the effect of implementing infection control guidelines on minimizing surgical wound infection for patients undergoing neurosurgery.

\subsection{Research hypothesis}

(1) Nurses' practices will be improved.

(2) Infection will be eradicated in neurosurgery department (in-patients) and neurosurgery operating theatres.

(3) No or small number of patients will develop surgical wound infection after neurosurgery.

\section{SUBJECTS AND METHODS}

Pretest/posttest was used to assess and evaluate nurses' practices pre and post implementation of infection control guidelines. Thirty-six nurses in neurosurgery department at Assiut Neurological, Psychiatric and Neurosurgery University Hospital (10 intraoperative nurses and 26 in-patients nurses) were included. Posttest only was used for patients to evaluate the effect of implementing infection control guidelines on minimizing surgical wound infection after neurosurgery. Patients with age ranged from 18-65 years were included in our study. Through a period of 6 months post implementation of infection control guidelines, 443 adult male and female patients undergoing different neurosurgical procedures with age ranged from 18-65 years were admitted to neurosurgery department and included in our study. Patients were assessed for the presence of surgical site infection during postoperative hospitalization period and for 3 months after neurosurgery. 


\subsection{Tools}

\section{Tool I: Pretest/posttest neurosurgery observation check- list for nurses' practices}

The researchers developed it after reviewing the literature. It was used to investigate preoperative, intraoperative and postoperative nurses' role. Four-point scale was used to assess and evaluate nurses' practices: (0) not done, (1) done incorrectly, (2) done correctly, and (3) not applicable. A score of $(\geq 75 \%)$ was considered adequate practice. It included:

(1) Preoperative practices (12 items): It consisted of items concerning hand washing ( 8 items), preparation of the patient (3 items) and proper administration of prescribed antibiotic (1 item).

(2) Intraoperative practices (78 items): It consisted of items concerning surgical hand rub (16 items), surgical attire and drapes (23 items), preparing sterile field (10 items), sterile field maintenance (10 items), prohibit eating and drinking by staff in operating theatres environment (1item), decrease movement in operating theatres environment ( 2 items), adequate ventilation of the operating rooms ( 3 items), cleaning and disinfection of environmental surfaces (4 items), sterilization of surgical instruments (4 items), and waste and linen management (5 items).

(3) Postoperative practices (50 items): It consisted of items concerning hand washing (8 items), safe environment to receive the patient (4 items), proper administration of prescribed antibiotic (1 item), disinfect the surface of the dressing trolley with antiseptic solution (1 item), postoperative wound care (18 items) and preparing patients for home care (teaching patients before discharge about wound care and dressing change) (18 items).

\section{Tool II: Assessment sheet for patients undergoing neuro- surgery}

It was developed by the researchers and was concerned with demographic, preoperative, operative and early postoperative data.

Preoperative data included shaving of hair, preoperative antibiotic, type of neurosurgery, history of previous neurosurgery, risk factors for surgical wound infection and length of preoperative stay.

Operative data included rule of surgery, intraoperative drain, intraoperative blood loss, blood transfusion, foreign body insertion (devices or instruments) and duration of surgery.

Postoperative data included postoperative antibiotic, wound healing, postoperative cerebrospinal fluid leak, onset, type and manifestations of wound infection if present and length of postoperative stay.

\section{Tool III: Follow up sheet for patients after neurosurgery}

It was developed by the researchers and was concerned with late postoperative data.

It included wound healing, cerebrospinal fluid leak and onset, type and manifestations of wound infection if present.

\section{Neurosurgery infection control guidelines (teaching booklet)}

We developed infection control guidelines based on World Health Organization, Australian and Asia Pacific Society Guidelines for Disinfection, Sterilization of Instruments and Prevention and Control of Wound Infection. ${ }^{[6,16,17]}$ The researchers developed and translated it into Arabic according to the needed nurses' practices that can help nurses in the provision of a safe and effective care for patients undergoing neurosurgery and reduce surgical wound infection. Infection control guidelines include preoperative, intraoperative and postoperative practices; infection risks, interventions and control strategies. Safety considerations include patients, visitors, and hospital staff. Hand washing, surgical hand rub, protective equipment, principles of asepsis, prevention of surgical site infection, preparing sterile field, sterile field maintenance, sterilization of surgical instruments, surgical attire and drapes, preoperative surgical site care, postoperative incision care, guidelines for cleaning and disinfection of environmental surfaces, and develop a good surveillance system to study incidence of surgical site infection during postoperative period and after discharge.

\subsection{Procedures}

To conduct our study, formal agreement was obtained from the local ethical committee and the head of the neurosurgery department. After explaining the aim of the study to both nurses and patients, oral permission for voluntary participation was obtained.

Confidentiality and anonymity were assured. Nurses and patients were informed that their names were coded during data entry. The researchers respected nurses and patients for privacy. They were provided with opportunities to discuss their questions and concerns regarding our study.

Three medical surgical nursing staff and 2 neurosurgery staff were engaged in reviewing study content. Correlation coefficient was used to test reliability (0.86). So, study content was valid and reliable.

Pilot study was conducted on $10 \%$ of sample for the purpose of testing study feasibility and clarity. No changes were done, so this sample was included in the study.

Nurses' practices for infection control guidelines were ob- 
served while performing all procedures and caring for neurosurgery patients at all levels of care (preoperative, intraoperative, and postoperative) before implementation of infection control guidelines (Tool I).

Neurosurgery infection control guidelines (teaching booklet) was introduced to all nursing staff caring for patients at all levels of care (preoperative, intraoperative, and postoperative) in neurosurgery department. The researchers explained infection control guidelines to nurses who were divided into small groups (2-3 nurses). Three teaching and training sessions were conducted by the researchers for in-patients nurses while 5 teaching and training sessions were conducted for intraoperative nurses. Time of each teaching and training session was 1 hour including discussion and feedback.

The researchers trained in-patients nurses about hand washing, using personal protective equipment, preparing sterile field, maintain sterility of sterile objects, wound dressing and irrigation, waste and linen management and cleaning and disinfection of environmental surfaces. Intraoperative nurses were trained about surgical hand rub, surgical attire and drapes, preparing sterile field, maintain sterility of sterile objects, waste and linen management and cleaning and disinfection of environmental surfaces.

Each nurse was given a hard copy of the teaching booklet (neurosurgery infection control guidelines). Nurses' practices for infection control guidelines were observed at all levels of care (preoperative, intraoperative, and postoperative) after implementation of infection control guidelines (Tool I).

Environmental swabs were taken from neurosurgery department (in-patients) and operating theaters for 1 time post implementation of infection control guidelines.

After implementation of infection control guidelines, all patients admitted to neurosurgery department for a period of 6 months with age ranged from 18-65 years were included in our study. Four hundred and forty-three adult male and female patients undergoing different neurosurgical procedures were included. Patients undergoing different neurosurgical procedures were visited daily after admission till discharge to assess for preoperative, intraoperative and postoperative data (Tool II).

The researchers were doing follow up for patients for a period of 3 months to evaluate surgical wound condition (Tool III). Some patients reported manifestations of wound infection to researchers by phone and the researchers advised them to attend to neurosurgery outpatient clinic to receive appropriate wound management and those patients attended and received appropriate management. More than one quarter of patients

Published by Sciedu Press followed up by phone and reported no wound infection and normal wound healing according to neurosurgeons reports which they contacted them in their private clinics.

\subsection{Statistical analysis}

Data were tested for normality by Anderson-Darling test and for homogeneity variances before further analysis. Categorical variables described by number and percent. Continuous variables described by mean and standard deviation. Chisquare and fisher exact tests were used to compare between categorical variables. Mann-Whitney and $t$-test were used to compare between continuous variables. Because of small sample size in intraoperative nurses, Mann-Whitney was used to compare between intraoperative nurses' practices pre and post implementation of infection control guidelines. $p$-value considered statistically significant at $<.05$. The IBM SPSS 20.0 software was used for analysis of data.

\section{RESUltS}

Data were obtained from 36 nurses in neurosurgery department at Assiut Neurological, Psychiatric and Neurosurgery University Hospital (10 intraoperative nurses and 26 inpatients nurses). Intraoperative nurses included 10 females with mean age $29.43 \pm 12.89$ years and all of them having diploma degree. In-patients nurses included 21 females and 5 males with mean age $28.86 \pm 14.97$ years, 2 of them having bachelor degree while 24 of them having diploma degree.

The majority of in-patients and intraoperative nurses were attended previous training about prevention and control of infection and had more than 10 years of work experience. Non-statistical significant relation was found as regarding previous training about prevention and control of infection and in-patients and intraoperative nurses' practices ( $p$-value $.750, .843$ respectively). Non-statistical significant relation was found as regarding years of experience and in-patients and intraoperative nurses' practices ( $p$-value $.158, .391$ respectively).

As shown in Table 1, there was highly statistical significant difference as regarding preoperative and postoperative nurses' practices in relation to overall practices score pre and post implementation of infection control guidelines ( $p$-value $<.001$ ) in all items (hand washing, preparation of patients [surgical site care], proper administration of prescribed preoperative and postoperative antibiotic, safe environment, wound care and preparing patients for home care [teaching patients before discharge about wound care and dressing change]).

Figure 1 illustrated obvious highly statistical significant difference between level of in-patients nurses' practices pre and post implementation of infection control guidelines. All in- 
patients nurses had unfavorable level of practices pre imple- of them had favorable level of practices post implementation mentation of infection control guidelines while the majority of infection control guidelines.

Table 1. Comparison between in-patients nurses' practices pre and post implementation of infection control guidelines $(\mathrm{n}=$ 26)

\begin{tabular}{|c|c|c|c|}
\hline \multirow{2}{*}{ Preoperative and postoperative practices } & Pretest & Posttest & \multirow{2}{*}{$p$-value } \\
\hline & $\bar{x} \pm \mathrm{SD}$ & $\bar{x} \pm$ SD & \\
\hline \multicolumn{4}{|l|}{ Preoperative practices } \\
\hline Hand washing (Maximum score $=16$ ) & $7.73 \pm 1.87$ & $12.19 \pm 3.93$ & $<.001 * *$ \\
\hline Preparation of patients (surgical site care) (Maximum score $=6$ ) & $1.15 \pm 1.49$ & $6 \pm 1.0$ & $<.001^{* *}$ \\
\hline $\begin{array}{l}\text { Administer prescribed preoperative antibiotic within 30-60 minutes before } \\
\text { incision (Maximum score = 2) }\end{array}$ & $0.38 \pm 0.5$ & $2 \pm 0$ & $<.001^{* *}$ \\
\hline Total score of preoperative practices (Maximum score $=24$ ) & $9.26 \pm 3.86$ & $20.19 \pm 4.93$ & $<.001^{* *}$ \\
\hline \multicolumn{4}{|l|}{ Postoperative practices } \\
\hline Hand washing (Maximum score $=16$ ) & $7.04 \pm 1.73$ & $12.15 \pm 3.96$ & $<.001^{* *}$ \\
\hline Safe rooms’ environment to receive patients (Maximum score $=8$ ) & $3.92 \pm 1.02$ & $7.85 \pm 0.61$ & $<.001 * *$ \\
\hline Wound care (Maximum score = 36) & $17.54 \pm 4.65$ & $32.15 \pm 7.2$ & $<.001 * *$ \\
\hline $\begin{array}{l}\text { Disinfect the surface of the dressing trolley with antiseptic solution (Maximum } \\
\text { score = 2) }\end{array}$ & $0.56 \pm 0.72$ & $1.57 \pm 0.53$ & $<.001^{* *}$ \\
\hline Administer prescribed postoperative antibiotic (Maximum score $=2$ ) & $0.54 \pm 0.51$ & $1.54 \pm 0.51$ & $<.001^{* *}$ \\
\hline $\begin{array}{l}\text { Preparing patients for home care (teaching patients before discharge about wound } \\
\text { care and dressing change) (Maximum score }=36 \text { ) }\end{array}$ & $2.78 \pm 2.72$ & $36 \pm 0$ & $<.001^{* *}$ \\
\hline Total score of postoperative practices (Maximum score $=100$ ) & $32.38 \pm 11.35$ & $91.26 \pm 12.81$ & $<.001 * *$ \\
\hline
\end{tabular}

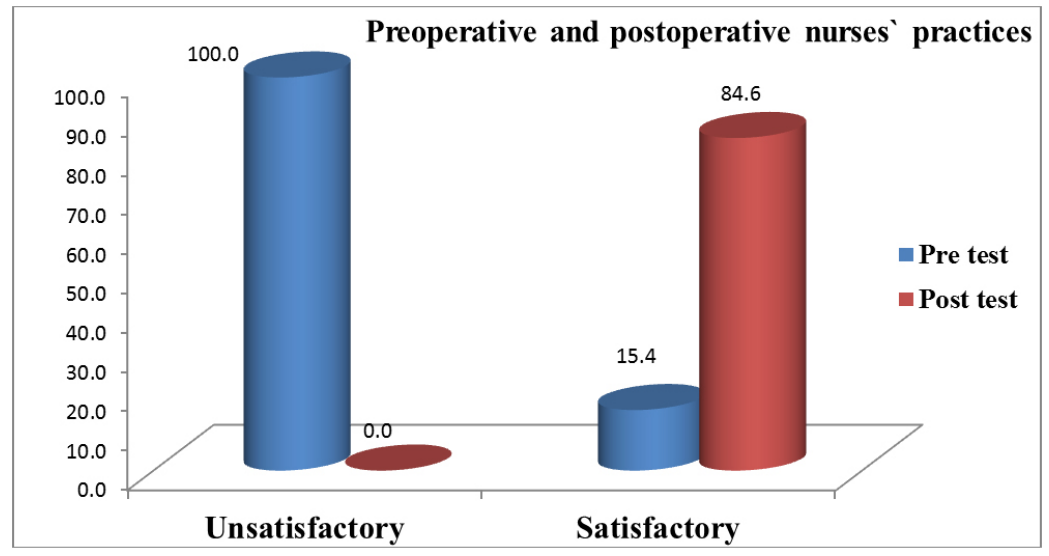

Figure 1. Level of preoperative and postoperative nurses' practices pre and post implementation of infection control guidelines

As shown in Table 2, highly statistical significant difference was found between intraoperative nurses' practices in relation to total practices score pre and post implementation of infection control guidelines $(p$-value $<.001)$. Intraoperative nurses' practices which showed highly statistical significant differences included: surgical hand rub, surgical attire and drapes, sterile field maintenance, adequate ventilation of the operating rooms, prohibit eating and drinking by staff in operating theatres environment, decrease movement in operating theatres environment, cleaning and disinfection of environmental surfaces and waste and linen management. Statistical significant difference was found regarding sterilization of surgical instruments pre and post implementation of infection control guidelines ( $p$-value .033). Non-statistical significant difference was found regarding preparing sterile field pre and post implementation of infection control guidelines ( $p$-value .123). 
Table 2. Comparison between intraoperative nurses' practices pre and post implementation of infection control guidelines $(\mathrm{n}=10)$

\begin{tabular}{|c|c|c|c|}
\hline \multirow{2}{*}{ Intraoperative practices } & Pretest & Posttest & \multirow{2}{*}{$p$-value } \\
\hline & $\bar{x} \pm$ SD & $\bar{x} \pm$ SD & \\
\hline Surgical hand rub (Maximum score $=32$ ) & $20 \pm 3.68$ & $24.1 \pm 2.42$ & $.004 * *$ \\
\hline Surgical attire and drapes (Maximum score $=46$ ) & $31.5 \pm 4.17$ & $45.9 \pm 0.32$ & $<.001 * *$ \\
\hline Preparing sterile field (Maximum score = 20) & $17.6 \pm 1.43$ & $18.6 \pm 1.35$ & .123 \\
\hline Sterile field maintenance (Maximum score = 20) & $12.5 \pm 2.12$ & $19.9 \pm 0.32$ & $<.001 * *$ \\
\hline Adequate ventilation of the operating rooms (Maximum score = 6) & $2.4 \pm 0.52$ & $4.2 \pm 0.42$ & $<.001 * *$ \\
\hline $\begin{array}{l}\text { Prohibit eating and drinking by staff in operating theatres environment } \\
\text { (Maximum score }=2 \text { ) }\end{array}$ & $1.2 \pm 0.42$ & $2 \pm 0$ & $<.001^{* *}$ \\
\hline Decrease movement in operating theatres environment $($ Maximum score $=4)$ & $2.2 \pm 0.63$ & $4 \pm 0$ & $<.001^{* *}$ \\
\hline Cleaning and disinfection of environmental surfaces (Maximum score $=8$ ) & $6.2 \pm 0.63$ & $8 \pm 0$ & $<.001 * *$ \\
\hline Sterilization of surgical instruments (Maximum score = 8) & $6.9 \pm 1.29$ & $7.8 \pm 0.63$ & $.033^{*}$ \\
\hline Waste and linen management (Maximum score = 10) & $7.3 \pm 0.95$ & $10 \pm 0$ & $<.001 * *$ \\
\hline Total score $($ Maximum score $=156$ ) & $107.8 \pm 8.18$ & $144.5 \pm 2.8$ & $<.001^{* *}$ \\
\hline
\end{tabular}

Figure 2 illustrated highly statistical significant difference between level of intraoperative nurses' practices pre and post implementation of infection control guidelines. The majority of intraoperative nurses had unsatisfactory level of practices before implementation of infection control guidelines and all of them had satisfactory level of practices post implementation of infection control guidelines.

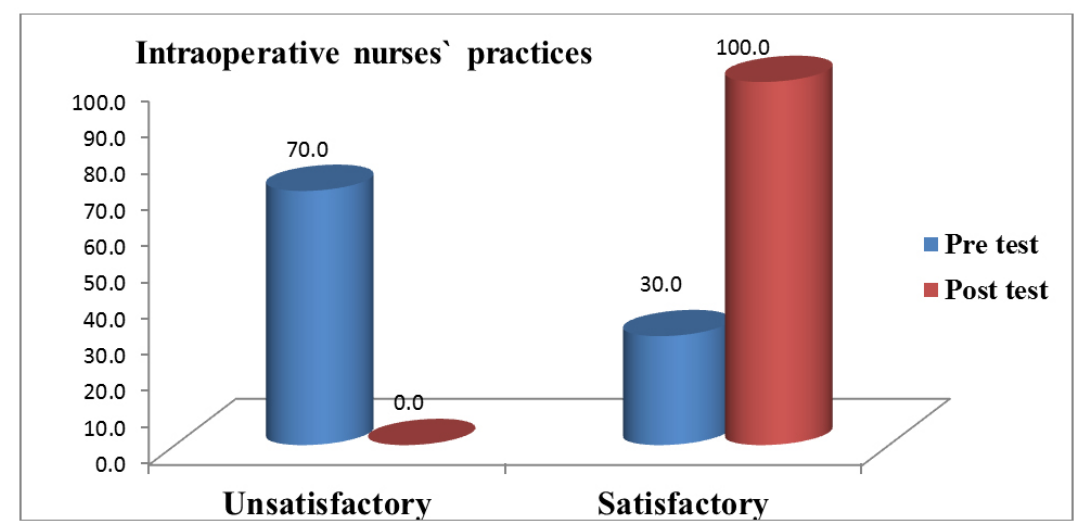

Figure 2. Level of intraoperative nurses' practices pre and post implementation of infection control guidelines

Figure 3 illustrated records of infection control unit and laboratory pre and post implementation of infection control guidelines. Over a period of 2 years pre implementation of infection control guidelines, environmental swabs were taken from neurosurgery department (in-patients) for 4 times and environmental swabs were taken from neurosurgery operating theaters for 6 times. Environmental swabs were taken from neurosurgery department (in-patients) and operating theaters for 1 time post implementation of infection control guidelines. High percent of infection was found in neurosurgery department (in-patients) and operating theaters pre implementation of infection control guidelines and zero percent of infection post implementation of infection control Published by Sciedu Press guidelines.

Data were obtained from 443 patients undergoing neurosurgery their age ranged from 18-65 years with mean age $41.3 \pm 13.9$ years. There were 246 males and 197 females.

Various types of neurosurgical procedures were performed to 443 patients. Spine surgery was performed for more than one quarter of patients 125 (28.2\%), also craniotomy was performed for more than one quarter of patients 121 (27.3\%), followed by ventriculoperitoneal shunt 78 (17.6\%), burr holes $64(14.4 \%)$, instrumental spine surgery (fixation with prosthesis) $41(9.2 \%)$, craniectomy $12(2.7 \%)$, and lumboperitoneal shunt $2(0.4 \%)$. 


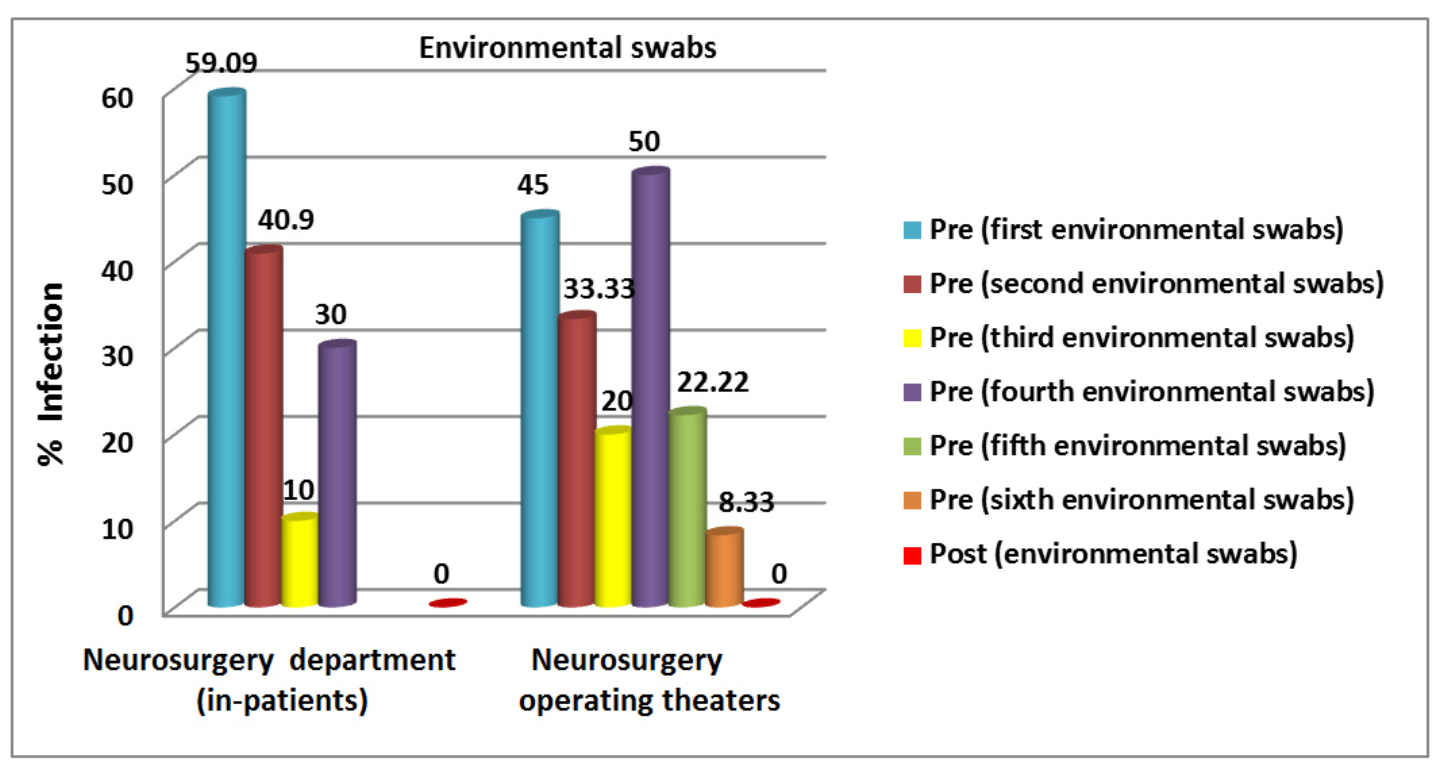

Figure 3. Percent of infection in neurosurgery department (in-patients) and neurosurgery operating theaters pre and post implementation of infection control guidelines

As shown in Table 3, smoking and foreign body insertion were encountered in more than one quarter of patients 124 (28.0\%) and $121(27.3 \%)$ respectively. Diabetes mellitus was encountered in $88(19.9 \%)$, followed by corticosteroid administration $12(2.7 \%)$, cerebrospinal fluid leak $11(2.48 \%)$ and obesity $2(0.5 \%)$.

Table 3. Risk factors for surgical wound infection of patients undergoing neurosurgery $(n=443)$

\begin{tabular}{lll}
\hline Risk factors for wound infection & No. & \% \\
\hline Smoking & 124 & 28.0 \\
Diabetes mellitus & 88 & 19.9 \\
Cerebrospinal fluid leak & 11 & 2.48 \\
Corticosteroid administration & 12 & 2.7 \\
Obesity (body mass index $\geq 30)$ & 2 & 0.5 \\
Foreign body insertion (devices or instruments) & 121 & 27.3 \\
No risk factors for surgical wound infection & 85 & 19.18 \\
\hline
\end{tabular}

Regarding preoperative data, shaving of hair was performed the night before surgery for $203(45.8 \%)$ patients, $443(100 \%)$ patients were received preoperative antibiotic within 30-60 minutes before surgical incision and 84 (18.96\%) patients were having previous neurosurgery. The length of preoperative stay was $1.13 \pm 1.16$ days.

Insertion of intraoperative drain was done for 295 (66.6\%) patients, elective surgery was performed for $316(71.3 \%)$ patients, intraoperative blood loss was found in 175 (39.5\%) patients, 176 (39.7\%) patients received blood transfusion during surgery, $121(27.3 \%)$ patients with foreign body insertion (devices or instruments); shunt devices or screws and rod in spinal fixation. Forty-seven (10.6\%) patients performed surgery less than 1hour duration, 241 (54.4\%) patients performed surgery lasted from 1-2 hours and $155(35.0 \%)$ patients performed surgery more than 2 hours duration.

All patients $443(100 \%)$ received postoperative antibiotic, 55 (12.4\%) patients presented with postoperative cerebrospinal fluid leak, and postoperative urinary catheterization was inserted to 147 (33.2\%) patients. The length of postoperative stay was $4.60 \pm 3.37$ days.

Regarding late postoperative data, 11 (2.5\%) patients presented with cerebrospinal fluid leak, and 65 (14.67\%) patients presented with delayed wound healing. Highly statistical significant relation ( $p$-value .001) was found between risk factors for surgical site infection and delayed wound healing.

As shown in Table 4, surgical wound infection was encountered among 6 (1.4\%) patients out of 443 patients after neurosurgery. All of them presented with local pain, swelling and redness. The majority of them presented with fever and purulent wound discharge. The most common type is the superficial $5(83.3 \%)$ out of 6 patients.

As shown in Table 5, non-statistical significant relation was found between surgical wound infection and age and gender of patients ( $p$-value $.511, .580$ respectively).

As shown in Table 6, highly statistical significant relation ( $p$-value $<.001$ ) was found between surgical wound infection and cerebrospinal fluid leakage, obesity and insertion of foreign body. 
Table 4. Distribution and characteristics of surgical wound infection for patients after neurosurgery $(n=6)$

\begin{tabular}{lll}
\hline Surgical wound infection & & \\
\hline & No. & \% \\
\hline Present & 6 & 1.4 \\
Absent & 437 & 98.6 \\
\hline Characteristics (n = 6) & No. & \% \\
\hline & & \\
\hline Onset & 5 & 83.3 \\
One $\leq$ six weeks & 1 & 16.66 \\
More than six weeks- twelve weeks & & \\
Types & 5 & 83.3 \\
Superficial & 1 & 16.66 \\
Deep & & \\
Signs and symptoms (more than one) & & 100 \\
1. Local pain & 6 & 100 \\
2. Swelling & 6 & 100 \\
3. Redness & 6 & 83.3 \\
4. Fever & 5 & 83.3 \\
5. Purulent wound discharge & 5 & \\
\hline
\end{tabular}

As shown in Table 7, $5(83.3 \%)$ out of $6(100 \%)$ patients who diagnosed with surgical wound infection were performed ventriculoperitoneal shunt and this relation is of highly statistical significant value ( $p$-value .001). Half of patients $1(50 \%)$ out of $2(100 \%)$ who performed lumboperitoneal shunt diagnosed with surgical wound infection and this relation is of highly statistical significant value $(p$-value $<.001)$.

As shown in Table 8, $4(66.7 \%)$ out of $6(100 \%)$ patients with surgical wound infection had history of previous neurosurgery, this relation is of highly statistical significant value ( $p$-value <.001). Five $(83.3 \%)$ out of $6(100 \%)$ patients with surgical wound infection had 1-3 days preoperative hospital stay, this relation is of statistical significant value ( $p$-value $.025)$.

As shown in Table 9, $5(83.3 \%)$ out of $6(100 \%)$ patients with surgical wound infection were performed urgent surgery, this relation is of highly statistical significant value ( $p$-value .003). Delayed wound healing was observed in all patients with surgical wound infection $(p$-value $<.001)$. Two-thirds of patients with surgical wound infection had more than 7 days of postoperative hospital stay, this relation is of statistical significant value ( $p$-value .038).

Table 5. Relationship between surgical wound infection and demographic data of studied patients $(n=443)$

\begin{tabular}{|c|c|c|c|c|c|}
\hline \multirow{3}{*}{ Demographic data } & \multicolumn{5}{|c|}{ Surgical wound infection } \\
\hline & \multicolumn{2}{|c|}{ Yes $(n=6)$} & \multicolumn{2}{|c|}{ No $(n=437)$} & \multirow{2}{*}{$p$-value } \\
\hline & No. & $\%$ & No. & $\%$ & \\
\hline \multicolumn{6}{|l|}{ Age } \\
\hline $18<35$ years & 3 & 50.0 & 140 & 32.0 & \multirow{3}{*}{.511} \\
\hline $35<50$ years & 1 & 16.7 & 167 & 38.2 & \\
\hline 50-65 years & 2 & 33.3 & 130 & 29.7 & \\
\hline \multicolumn{6}{|l|}{ Gender } \\
\hline Male & 4 & 66.7 & 242 & 55.4 & \multirow[t]{2}{*}{.580} \\
\hline Female & 2 & 33.3 & 195 & 44.6 & \\
\hline
\end{tabular}

Table 6. Relationship between surgical wound infection and risk factors for surgical wound infection

\begin{tabular}{|c|c|c|c|c|c|}
\hline \multirow{3}{*}{ Risk factors (more than one) } & \multicolumn{5}{|c|}{ Surgical wound infection } \\
\hline & \multicolumn{2}{|c|}{ Yes $(n=6)$} & \multicolumn{2}{|c|}{ No $(n=437)$} & \multirow{2}{*}{$p$-value } \\
\hline & No. & $\%$ & No. & $\%$ & \\
\hline Smoking & 1 & 16.7 & 123 & 28.1 & .534 \\
\hline Diabetes mellitus & 1 & 16.7 & 87 & 19.9 & .843 \\
\hline Cerebrospinal fluid leak & 3 & 50.0 & 8 & 1.8 & $<.001 * *$ \\
\hline Corticosteroid administration & 0 & 0.0 & 12 & 2.7 & .681 \\
\hline Obesity (body mass index $\geq 30$ ) & 1 & 16.7 & 1 & 0.2 & $<.001 * *$ \\
\hline Foreign body insertion (devices or instruments) & 6 & 100.0 & 115 & 26.3 & $<.001 * *$ \\
\hline
\end{tabular}


Table 7. Relationship between surgical wound infection and types of neurosurgery $(n=443)$

\begin{tabular}{|c|c|c|c|c|c|}
\hline \multirow{3}{*}{ Types of neurosurgery } & \multicolumn{5}{|c|}{ Surgical wound infection } \\
\hline & \multicolumn{2}{|c|}{ Yes $(n=6)$} & \multicolumn{2}{|c|}{ No $(n=437)$} & \multirow{2}{*}{$p$-value } \\
\hline & No. & $\%$ & No. & $\%$ & \\
\hline Ventriculoperitoneal shunt $(n=78)$ & 5 & 83.3 & 73 & 16.7 & $.001^{* *}$ \\
\hline Lumboperitoneal shunt $(n=2)$ & 1 & 16.7 & 1 & 0.2 & $<.001 * *$ \\
\hline Burr holes $(n=64)$ & - & - & 64 & 14.4 & - \\
\hline Craniotomy $(\mathrm{n}=121)$ & - & - & 121 & 27.3 & - \\
\hline Craniectomy $(\mathrm{n}=12)$ & - & - & 12 & 2.7 & - \\
\hline Spine surgery $(\mathrm{n}=125)$ & - & - & 125 & 28.2 & - \\
\hline Instrumental spine surgery (fixation with prosthesis) $(n=41)$ & - & - & 41 & 9.2 & - \\
\hline
\end{tabular}

Table 8. Relationship between surgical wound infection and preoperative data of studied patients $(n=443)$

\begin{tabular}{|c|c|c|c|c|c|}
\hline \multirow{3}{*}{ Preoperative data } & \multicolumn{5}{|c|}{ Surgical wound infection } \\
\hline & \multicolumn{2}{|c|}{ Yes $(n=6)$} & \multicolumn{2}{|c|}{ No $(n=437)$} & \multirow{2}{*}{$p$-value } \\
\hline & No. & $\%$ & No. & $\%$ & \\
\hline \multicolumn{6}{|c|}{ Previous neurosurgery } \\
\hline Yes & 4 & 66.7 & 46 & 61.3 & $<.001^{* *}$ \\
\hline No & 2 & 33.3 & 391 & 521.3 & \\
\hline \multicolumn{6}{|c|}{ Length of preoperative stay } \\
\hline Less than one day & 0 & 0.0 & 72 & 16.5 & $.025 *$ \\
\hline 1-3 days & 5 & 83.3 & 357 & 81.7 & \\
\hline More than 3 days & 1 & 16.7 & 8 & 1.8 & \\
\hline
\end{tabular}

Table 9. Relationship between surgical wound infection and operative and postoperative data $(n=443)$

\begin{tabular}{|c|c|c|c|c|c|}
\hline \multirow{3}{*}{ Operative and postoperative data } & \multicolumn{5}{|c|}{ Surgical wound infection } \\
\hline & \multicolumn{2}{|c|}{ Yes $(n=6)$} & \multicolumn{2}{|c|}{ No $(n=437)$} & \multirow{2}{*}{$p$-value } \\
\hline & No. & $\%$ & No. & $\%$ & \\
\hline \multicolumn{6}{|l|}{ Rule of surgery } \\
\hline Elective & 1 & 16.7 & 315 & 72.1 & $.003^{* *}$ \\
\hline Urgent & 5 & 83.3 & 122 & 27.9 & \\
\hline \multicolumn{6}{|l|}{ Wound healing } \\
\hline Normal & 0 & 0.0 & 372 & 85.1 & $<.001 * *$ \\
\hline Delayed & 6 & 100.0 & 65 & 14.9 & \\
\hline \multicolumn{6}{|l|}{ Length of postoperative hospital stay } \\
\hline Less than 7 days & 2 & 33.3 & 339 & 77.6 & $.038 *$ \\
\hline More than 7 days & 4 & 66.6 & 98 & 22.3 & \\
\hline
\end{tabular}

\section{DisCussion}

Despite the great improvement in nursing and medical techniques and advances in infection control practices, surgical wound infection still a substantial cause for mortality and morbidity. ${ }^{[18]}$ Surgical wound infection after neurosurgery is a serious complication and requires immediate interven- tion. Nurses caring for neurosurgery patients at all levels of care (before, during and after surgery) have a crucial role in controlling surgical wound infection. ${ }^{[19]}$

In spite of most nurses were attended previous training about infection control and had many years of experience, they had unfavorable level of practices during pretest. The majority 
of them had favorable level of practices during posttest.

This could be explained by lack of continues training about infection control, lack of continues observation and evaluation of nurses' practices and most nurses were having diploma degree while small number was having bachelor degree. In our study, frequent guidance, education, training, observation and evaluation by the researchers showed a positive effect on nurses' practices. Neurosurgery nurses were aware of their continued observation and evaluation by the researchers and they were informed that they responsible to adhere to and implement infection control guidelines (teaching booklet and teaching and training sessions). So, nurses should be responsible and accountable for their practices.

To meet the healthcare needs of our patients, we must professionally accountable for expanding our clinical skill set and consistently implementing gold standard evidence-based practice findings to guide our nursing interventions. Ongoing clinical competency requires active participation to attain and maintain the skills necessary to provide exceptional care for our patients. We should present during each professional training session. This will allow us to clarify key points that may impact patient safety and outcomes. ${ }^{[20]}$

A periodic regular infection control round is very essential to identify improvement activities to ensure that nurses are adhering to established standards. ${ }^{[16]}$

Infection control guidelines (teaching booklet and teaching and training sessions) showed a significant effect on nurses' practices regarding infection control and this reflected on enhancing nurses' practices, eradicate infection in neurosurgery department (in-patients) and operating theaters and reduce surgical wound infection among patients after neurosurgery.

Several studies showed that providing training programs for nurses enhance different aspects of patients' care; reduce patient mortality, length of hospital stay, hospital readmission, healthcare associated infection, patient care costs, and other complications related to hospitalization. ${ }^{[21]}$ Good nurses' practices have a great effect on providing quality of care to patients and reducing surgical wound infection. ${ }^{[22]}$

Implementation of infection control educational program in addition to continuous assessment and evaluation had a significant role in reducing surgical wound infection after neurosurgery. ${ }^{[18]}$

Implementation of World Health Organization Guidelines can prevent surgical wound infection and promote the health of patients. Shaving of hair should only be done using a clipper the same day of surgery, in a location outside the operating room. Shaving hair the morning of surgery has resulted in fewer surgical site infections than shaving the day before surgery. Studies conducted over the last 30 years have demonstrated that preoperative shaving with the use of safety razors is a risk factor for surgical site infection. ${ }^{[6]}$ Other guidelines include: surgical site preparation, administration of appropriate antibiotic prophylaxis within 30-60 minutes before incision, preoperative showering, and wound management. ${ }^{[16]}$

Also, our study included 443 patients with different neurosurgical procedures with mean age $41.3 \pm 13.9$ years. More than half of our patients were males. More than one quarter of patients were performed spinal surgeries, also more than one quarter of patients were performed craniotomies, followed by ventriculoperitoneal shunt, burr holes, instrumental spine surgery (fixation with prosthesis), craniectomy and lumboperitoneal shunt.

Similar study was conducted on 1,181 patients with different neurosurgical procedures with mean age $33.9 \pm 19.6$ years. More than half of patients were males. The majority of patients were performed spine surgeries, followed by craniotomy, instrumental spine surgery, shunt surgeries and aneurysmal clips. ${ }^{[23]}$

The result of our study revealed that $6(1.4 \%)$ patients among 443 patients diagnosed with surgical wound infection following neurosurgery. This result was lower than the range that had been reported in the literature and in the previous 6 months records of neurosurgery department at Assiut Neurological, Psychiatric and Neurosurgery University Hospital before conducting our study (the effect of implementing infection control guidelines on minimizing surgical wound infection following neurosurgery).

Large number of patients $32(7.3 \%)$ out of 438 through a period of 6 months before conducting our study experienced surgical wound infection after various neurosurgical procedures. ${ }^{[15]}$ In addition to records and reports of infection control unit and laboratory at Assiut University Hospitals which illustrated the effect of implementing infection control guidelines on eradicate infection based on the results of environmental swabs that were taken from neurosurgery department (in-patients) and neurosurgery operating theaters thus reflected on minimizing surgical wound infection following neurosurgery. ${ }^{[24]}$

According to records of neurosurgery department at Assiut Neurological, Psychiatric and Neurosurgery University Hospital, the incidence of postoperative wound infection following different neurosurgical procedures was reduced after implementation of infection control guidelines (teaching and training sessions for nurses in addition to hard copies of 
teaching booklet) compared to the previous 6 months before conducting our study.

The incidence of surgical wound infection in other different studies showed that 43 (4.5\%) patients out of 949 patients presented with surgical wound infection following neurosurgery. ${ }^{[25]}$ Study of (Buang and Haspani, 2012) identified that $30(7.7 \%)$ patients among 390 patients diagnosed with wound infection post craniotomy. ${ }^{[26]}$ A total of $119(8.5 \%)$ patients among 1407 patients presented with wound infection following various types of neurosurgery. ${ }^{[19]}$

A dequate ventilation of the operating rooms, improvement of sterilization methods and surgical techniques showed advanced infection control, but complete eradication of infection in postsurgical patients is difficult to accomplish. ${ }^{[26]}$ Prevention of surgical site infection has to be done at many levels, especially with patients undergoing long surgical procedures. $^{[27]}$

In our study, all patients received preoperative and postoperative antibiotic prophylaxis according to hospital policy. Other infection control measures were carried out by nurses according to infection control guidelines (teaching booklet and teaching and training sessions). Despite these infection control measures, 6 patients with surgical wound infection were detected.

This might be as a result of incomplete adherence of all healthcare team to infection control guidelines. Implementing infection control guidelines require coordinated multidisciplinary team. After discharge, some patients did not show much interest in caring for wound and did not adhere completely to medical and nursing instructions concerning wound care and also the presence of risk factors.

Similar study reported that all patients received antibiotic prophylaxis according to the agency protocol. Despite this infection control measure, 8 cases out of 85 developed surgical wound infection, probably due to presence of other risk factors. ${ }^{[28]}$ Correct antibiotic prophylaxis requires administering the prescribed antibiotic within 30-60 minutes before surgery and its discontinuation within 24 hours after surgery. ${ }^{[29,30]}$

Highly statistical significant relation was found between surgical wound infection and cerebrospinal fluid leak, obesity, foreign body insertion (shunt surgeries) and history of previous neurosurgery. Statistical significant relation was found between surgical wound infection and total length of hospital stay.

Length of hospital stay, obesity and blood transfusion were associated with surgical wound infection. ${ }^{[28]}$
Prolonged preoperative hospitalization, large size of incision, prolonged duration of surgical procedure, high number of personnel involved in surgery and instrumental neurosurgery were associated with surgical wound infection. ${ }^{[31]}$ Patients presented with surgical wound infection had significantly longer hospital stay. ${ }^{[27]}$

Identification of risk factors help to improve care of patients, reduce mortality, morbidity and healthcare cost. Post neurosurgery surveillance is important to identify risk factors. ${ }^{[32]}$

In our study, superficial wound infection is the most common type followed by the deep one. Patients presented with local pain, swelling and redness. The majority of them presented with fever and purulent wound discharge.

Similar study revealed that superficial wound infection is the most common type followed by deep then organ/space infections. Patients presented with purulent drainage followed by redness, fever, localized pain and swelling. ${ }^{[26]}$

Highly statistical significant relation was found between risk factors and delayed wound healing. Patients with delayed wound healing presented with one or more risk factors (smoking, foreign body insertion, diabetes mellitus, corticosteroid administration, cerebrospinal fluid leak and/or obesity). Delayed wound healing was observed in all patients with surgical wound infection.

Similar study concluded that factors leading to wound healing problems in neurosurgical patients are primary disease, prolonged administration of cortisone and cerebrospinal fluid leak. ${ }^{[33]}$

Shaving of hair was performed the night before surgery for less than half of patients using a clipper included 4 patients from those who developed surgical wound infection in our study. In neurosurgery department shaving of hair for patients was performed with a clipper the night before surgery.

Avoid using razors to remove hair before surgery, hand hygiene and strict aseptic technique during dressing are critical in preventing/reducing surgical wound infection. ${ }^{[34]}$

Highly statistical significant relation was found between surgical wound infection and urgent operations. Most patients who developed surgical wound infection performed urgent operations.

Similar study demonstrated that surgical wound infection more likely occurred in patients performed emergency operations with statistical significant value. ${ }^{[18]}$

In our study, teaching patients before discharge about wound care and dressing change had a positive role in reducing wound infection. For patients who developed surgical wound 
infection, teaching patients before discharge about wound care and dressing change was played a significant role in early detection and management of surgical site infection and thus prevented further complications.

Before discharge, nurse must accurately review postoperative instructions with patients for the purpose of preventing/reducing surgical wound infection. ${ }^{[6]}$

\section{Limitations}

Lack of control group of patients because the necessity for urgent implementation of infection control guidelines to overcome the high percent of infection based on records of environmental swabs that were taken from neurosurgery department (in-patients) and neurosurgery operating theatres and the records of high percent of postoperative wound infection compared to previous 6 months before conducting our study.

Incomplete adherence to infection control guidelines (some nurses didn't perform all steps correctly), even when associated with checklist and issue that can be limited by patients' risk factors. Adherence can be limited by lack of awareness of infection control guidelines by members of the multidisciplinary healthcare team.

In neurosurgery department shaving of hair for patients un- dergoing intracranial surgery was performed by a barber using a clipper the night before surgery.

Environmental swabs were taken just for 1 time [post implementation of infection control guidelines]. No further environmental swabs were taken because of its high hospital costs.

\section{CONCLUSION AND RECOMMENDATIONS}

Continuous assessment and evaluation for healthcare team is necessary in maintaining effective high quality care and preventing or reducing surgical wound infection.

Commitment to infection control guidelines is the responsibility of each member of the healthcare team and it is essential to achieve our goal in preventing or reducing surgical wound infection after neurosurgery. Continued surveillance is essential for the evolution of evidence-based prevention rules and as a strong tool for prevention of surgical wound infection. Mandatory training of all healthcare team must be encouraged to improve the surveillance system and adherence rate.

\section{CONFLicts OF INTEREST Disclosure}

\section{REFERENCES}

[1] Ban KA, Minei JP, Laronga C, et al. American College of Surgeons and Surgical Infection Society: Surgical Site Infection Guidelines. Journal of the American College of Surgeons. 2017; 224(1): 59. https://doi.org/10.1016/j.jamcollsurg. 2016.10.029

[2] Edwards JR, Peterson KD, Mu Y, et al. National Healthcare Safety Network (NHSN). American Journal of Infection Control. 2009; 37(10): 783-805.

[3] Wilson J. How to reduce the risk of surgical site infection. Nursing Times. 2015; 111(38): 12-16.

[4] Meng F, Cao J, Meng X. Risk factors for surgical site infections following spinal surgery. Journal of Clinical Neuroscience. 2015; 22(12): 1862-1866. https://doi.org/10.1016/j.jocn.2015.03.065

[5] Fee E, Garofalo ME. Florence nightingale and the Crimean War. American Journal of Public Health. 2010; 100(9): 1591. https: //doi.org/10.2105/AJPH. 2009.188607

[6] World Health Organization. Global guidelines for the prevention of surgical site infection. 2016.

[7] Agodi AF. Operating theatre ventilation systems and microbial air contamination in total joint replacement surgery: results of the GISISChIA study. Journal of Hospital Infection. 2015; 90(3): 213-219. https://doi.org/10.1016/j.jhin.2015.02.014

[8] Wilson J. Surgical site infection: the principles and practice of surveillance, Part 1: key concepts in the methodology of SSI surveillance. Journal of Infection Prevention. 2013; 14(1): 6-12. https://doi.org/10.1177/1757177412471147

Published by Sciedu Press
[9] Wilson J. Surgical site infection: the principles and practice of surveillance, Part 2: analyzing and interpreting data. Journal of Infection Prevention. 2013; 14(6): 198-202. https://doi.org/10.1177/ 1757177413507620

[10] Loyola University Health System. Surgical site infections are the most common and costly of hospital infections: Guidelines for preventing surgical site infections are updated. Science Daily. 2017.

[11] Kneedler JA, Pfister JI, Austin P, et al. Preoperative Hair Removal: Impact On Surgical Site Infections, Published article. Pfiedler Enterprises. 2012.

[12] Singhal H, Geibel J. Wound Infection Treatment and Management, Published article, MD LLC. 2014.

[13] Assiut Neurological, Psychiatric and Neurosurgery University Hospital Records. Environmental surfaces swabs, Neurosurgery Department; In-patients and operating theaters, Infection Control Unit and Laboratory. 2014.

[14] Assiut Neurological, Psychiatric and Neurosurgery University Hospital Records. Environmental surfaces swabs, Neurosurgery Department; In-patients and operating theaters, Infection Control Unit and Laboratory. 2015.

[15] Assiut Neurological. Psychiatric and Neurosurgery University Hospital Records. Neurosurgery Department. 2016.

[16] Australian guidelines for the prevention and control of infection in healthcare. National Health and Medical Research Council. 2010.

[17] Asia Pacific Society of Infection Control. Guidelines for Disinfection and Sterilization of Instruments in Health Care Facilities. 2016. 
[18] Jiang X, Ma J, Hou F, et al. Neurosurgical site infection prevention: single institute experience. Turk Neurosurg. 2016; 26(2): 234-239.

[19] Hussain TG. Bundle approach for prevention and control of surgical site infection in neurosurgical patients, Master thesis, Neurosurgery department, Faculty of Medicine. Assiut University. 2012.

[20] Davis C. The importance of professional account ability. Nursing Made Incredibly Easy. 2017; 15(6): 4. https://doi.org/10.109 7/01. NME.0000525557.44656.04

[21] Assi MJ, Artz M, Haebler J, et al. Optimal Nurse Staffing to Improve Quality of Care and Patient Outcomes. American Nurses Association, Avalere Health LLC: Executive Summary. 2015.

[22] Sadia H, kousar R, Azhar M, et al. Assessment of Nurses' Knowledge and Practices Regarding Prevention of Surgical Site Infection. Saudi Journal of Medical and Pharmaceutical Sciences. 2017; 3(6): 585-595.

[23] Taha MM, Abouhashem S, Abdel-Rahman AY. Neurosurgical wound infection at a university hospital in Egypt: prospective study of 1,181 patients for 2 years. Turkish Neurosurgery. 2014; 24(1): 8-12.

[24] Assiut Neurological, Psychiatric and Neurosurgery University Hospital Records. Environmental surfaces swabs, Neurosurgery Department: In-patients and operating theaters. Infection Control Unit and Laboratory. 2016.

[25] Cassir N, De La Rosa S, Melot A, et al. Risk factors for surgical site infections after neurosurgery: A focus on the postoperative period. American Journal of Infection Control. 2015; 43(12): 1288-1291. https://doi.org/10.1016/j.ajic.2015.07.005

[26] Buang SS, Haspani MS. Risk factors for neurosurgical site infections after a neurosurgical procedure: a prospective observational study at Hospital Kuala Lumpur. Med J Malaysia. 2012; 67(4): 393-398.

[27] Abu Hamdeh S, Lytsy B, Ronne-Engström E. Surgical site infections in standard neurosurgery procedures-a study of incidence, impact and potential risk factors. British Journal of Neurosurgery. 2014; 28(2): 270-275. https://doi .org/10.3109/02688697.2013.835376

[28] Bellusse GC, Ribeiro JC, Campos FRD, et al. Risk factors for surgical site infection in neurosurgery. Acta Paulista de Enfermagem. 2015; 28(1): 66-73.

[29] O'Neill KR, Smith JG, Abtahi AM, et al. Reduced surgical site infections in patients undergoing posterior spinal stabilization of traumatic injuries using vancomycin powder. Spine J. 2011; 11(7): 641-646. https://doi.org/10.1016/j.spinee.2011.04.025

[30] Chaichana KL, Bydon M, Santiago-Dieppa DR, et al. Risk of infection following posterior instrumented lumbar fusion for degenerative spine disease in 817 consecutive cases. J Neurosurg Spine. 2014; 20(1): 45-52. https ://doi.org/10.3171/2013.10.SPINE136

[31] Schwender JD, Casnellie MT, Perra JH, et al. Perioperative complications in revision anterior lumbar spine surgery: incidence and risk factors. Spine J. 2009; 34(1): 87-90. https ://doi .org/10.1097/ BRS. Ob013e3181918ad0

[32] Mcgirt MJ, Godil SS. Reduction of surgical site infection in spine surgery: an opportunity for quality improvement and cost reduction. Spine J. 2013; 13(9): 1030-1031. https : //doi .org/10.1016/j . spinee. 2013.06 .003

[33] Krishnan KG, Müller A, Hong B, et al. Complex wound-healing problems in neurosurgical patients: risk factors, grading and treatment strategy. Acta Neurochirurgica. 2012; 154(3): 541-554. https : //doi.org/10.1007/s00701-011-1221-0

[34] Anderson DJ, Podgorny K, Berrios-Torres SI. Strategies to prevent surgical site infections in acute care hospitals. Infection Control Hospital Epidemiology. 2014; 35(6): 605-627. https ://doi .org/10 $.1086 / 676022$ 